\title{
Human cationic amino acid transporters are not affected by direct nitros(yl)ation
}

\author{
Anastasia J. Hobbach ${ }^{1}$ Ellen I. Closs ${ }^{1}$
}

Received: 28 June 2019 / Accepted: 20 January 2020 / Published online: 1 February 2020

(c) The Author(s) 2020

\begin{abstract}
A direct inhibiting effect of NO on the function of CAT-1 and -2A has been postulated to occur via nitrosylation of cysteine residues in the transporters. Neither the NO donor SNAP nor a mixture of SIN-1 and Spermine NONOate, that generates the strong nitrosating agent $\mathrm{N}_{2} \mathrm{O}_{3}$, reduced CAT-mediated L-arginine transport. Direct nitros(yl)ation does either not occur in CATs or does not affect their transport function. A regulatory effect of NO or nitrosating agents on CAT-mediated transport under physiological conditions seems, therefore, unlikely.
\end{abstract}

Keywords Nitric oxide donors $\cdot$ SNAP $\cdot$ SIN-1 $\cdot$ SPENO $\cdot$ Arginine $\cdot$ Xenopus laevis oocytes $\cdot$ Nitrosylation $\cdot$ Nitrosation

$\begin{array}{ll}\text { Abbreviations } \\ \text { CAT } & \begin{array}{l}\text { Cationic amino acid transporter (SLC7A1-A3, } \\ \text { prefix: human) }\end{array} \\ \text { CAA } & \begin{array}{l}\text { Cationic Amino Acids } \\ \text { cRNA }\end{array} \\ \text { RNA transcribed from cDNA } \\ \text { GSH } & \text { Reduced glutathione } \\ \text { GSNO } & \text { S-Nitrosoglutathione } \\ \text { HPLC } & \text { High-performance liquid chromatography } \\ \text { IUGR } & \text { Intrauterine growth restriction } \\ \text { NEM } & N \text {-Ethylmaleimide } \\ \text { PKC } & \text { Protein kinase C } \\ \text { SLC7 } & \text { Solute carrier family 7 } \\ \text { SIN-1 } & \text { 5-Amino-3-(4-morpholinyl)-1,2,3-oxadiazolium } \\ & \text { chloride } \\ \text { SNAP } & \text { S-Nitroso- } N \text {-acetylpenicillamine }\end{array}$

Handling editor: D. Zilberstein.

The manuscript contains major parts of the doctoral thesis of Anastasia J. Hobbach.

Electronic supplementary material The online version of this article (https://doi.org/10.1007/s00726-020-02819-2) contains supplementary material, which is available to authorized users.

Ellen I. Closs

closs@uni-mainz.de

1 Department of Pharmacology, University Medical Center of the Johannes Gutenberg University Mainz, Langenbeckstraße 1, 55131 Mainz, Germany
SNO S-Nitrosothiols

SPENO Spermine NONOate; (Z)-1-[N-[3-aminopropyl]$\mathrm{N}$-[4-(3-aminopropylammonio)butyl]-amino] diazen-1-ium-1,2-diolate

\section{Introduction}

Cationic amino acid transporters (CATs, SLC7A1-3) mediate specifically the transport of cationic amino acids (CAA) such as L-arginine. In most cells, they are the main CAA import route and are thus essential for all metabolic pathways involving these amino acids (Closs et al. 2006), e. g. the synthesis of proteins, urea, $\mathrm{NO}$ and creatine ( $\mathrm{Lu}$ et al. 2009). Previous studies have shown that CATs are inhibited by $N$-ethylmaleimide (NEM) that acts on two defined cysteine residues conserved in all mouse and human CAT proteins corresponding to Cys 33 and 273 in human CAT2A (Beyer et al. 2013; Devés et al. 1993). These cysteine residues are thus essential for transporter function and consequently a probable target by endogenous mediators to regulate transporter activity.

In rat cardiac myocytes, inhibition of both low- and highaffinity arginine transport through nitric oxide has been observed and it has been suggested that this inhibition was mediated by S-nitros(yl)ation of cysteine residues in CAT-1 and CAT-2A (Zhou et al. 2010). As transport inhibition by exogenous NO has also been observed in myocyte-derived membrane vesicles lacking all intracellular components such as CAA, or soluble enzymes, a direct interaction between 
$\mathrm{NO}$ and the transporters has been proposed. S-nitros(yl)ation is the redox-based formation of S-nitrosothiols (SNO) in cysteine residues in proteins (or smaller molecules such as glutathione, GSH) that may lead to pronounced structural and functional changes (Foster et al. 2003). SNO formation can be achieved by reaction of either NO with cysteine thiyl radicals (known to be present in a number of proteins) or of nitrosating agents with cysteine thiol (Heinrich et al. 2013). Alternatively, SNO may be generated by a process called trans-nitrosation from nitros(yl)ated small molecules (e. g. S-nitrosoglutathione, GSNO) or other proteins (Heinrich et al. 2013). A powerful nitrosating agent is dinitrogen trioxide $\left(\mathrm{N}_{2} \mathrm{O}_{3}\right)$ that can be formed from $\mathrm{NO}$ and $\mathrm{O}_{2}{ }^{-}$. The physiological concentrations of the two reactants are considered to be too low for the reaction to occur efficiently in the aqueous environment of the cytoplasm. However, both compounds accumulate in the hydrophobic milieu of the plasma membrane thus accelerating $\mathrm{N}_{2} \mathrm{O}_{3}$ formation and subsequent nitrosation (Liu et al. 1998). As CATs are integral membrane proteins, S-nitros(yl)ation seems a plausible mechanism of transporter regulation. The aim of our current study was, therefore, to identify the cysteine residues responsible for transporter inhibition by $\mathrm{NO} /$ nitros(yl)ation.

\section{Materials and methods}

\section{$\mathrm{L}-\left[{ }^{3} \mathrm{H}\right]$ arginine uptake}

Isolation of Xenopus laevis oocytes (approved by the Rhineland-Palatinate Investigative Office, A 12-1-002) and injection with cRNA coding for hCAT-1 or hCAT-2A (or with water only for baseline correction) were performed as previously described (Beyer et al. 2013). The injected oocytes were incubated in modified Leibovitz medium for 2 days at $18{ }^{\circ} \mathrm{C}$ to enable protein expression. Oocytes were then rinsed three times with ice-cold uptake solution ND96 $(96 \mathrm{mM}$ $\mathrm{NaCl}, 1.8 \mathrm{mM} \mathrm{CaCl}_{2}, 2 \mathrm{mM} \mathrm{KCl}, 1 \mathrm{mM} \mathrm{MgCl} 2,10 \mathrm{mM}$ HEPES, pH 7.3) and subsequently incubated for $10 \mathrm{~min}$ in ND96 in the absence or presence of $100 \mu \mathrm{M}$ SNAP (Sigma Aldrich, Deisenhofen, Germany) or $1 \mathrm{mM}$ each, Sin-1 and SPENO (both Cayman Chemical, Ann Arbor, USA), as indicated. With SNAP being light sensitive, incubation tubes were wrapped with aluminum foil during the experiments.

hCAT activity was determined by measuring either $100 \mu \mathrm{M}$ (hCAT-1) or $1 \mathrm{mM}$ (hCAT-2A) L- $\left[{ }^{3} \mathrm{H}\right]$ arginine $(10 \mu \mathrm{Ci} / \mathrm{ml}$, ICN Biomedicals $\mathrm{GmbH}$, Eschwege, Germany) uptake in the continuous presence or absence of the respective $\mathrm{NO} / \mathrm{O}_{2}{ }^{-}$donor. The time points within the linear range of initial uptake were determined by performing a time-course. Incubation times were $15 \mathrm{~min}$ for experiments performed at $20^{\circ} \mathrm{C}$, and $1 \mathrm{~min}$ (hCAT-1) or $3 \mathrm{~min}$ (hCAT2A) for experiments performed at $37{ }^{\circ} \mathrm{C}$. The uptake was stopped by transferring the incubation tubes on ice followed by immediate washing three times with ice-cold ND96. Oocytes were then solubilized in 2\% SDS and radioactivity was determined by scintillation counting.

\section{Quantification of GSH and GSNO}

3 oocytes each were lysed in $500 \mu$ borate buffer and GSH to GSNO concentrations were determined in $50 \mu \mathrm{l}$ lysate, each, using an HPLC-based method as previously described (Tsikas et al. 1999), except that NEM was supplemented at a final concentration of $1 \mathrm{mM}$ where suitable. GSNO was determined as GSH peak after treatment of oocyte lysates with NEM (reacts with free GSH) and subsequent 2-mercaptoethanol (transforms GSNO, but also oxidized glutathione to GSH). GSNO generated by exposure to Sin-1/SPENO was quantified by subtracting the GSH peak obtained after NEM and 2-mercaptoethanol treatment of lysates of untreated oocytes from the corresponding peak of Sin-1/ SPENO-exposed oocytes thereby canceling the endogenous background of oxidized glutathione and GSNO (Supplemental Fig. 1).

\section{Statistical analyses}

For statistical analyses, the mean amount of $\mathrm{L}-\left[{ }^{3} \mathrm{H}\right]$ arginine taken up by the respective batch of oocytes without exogenous transporter expression was subtracted from the value obtained for each transporter-expressing oocyte of the same batch. Values for each individual oocyte were then calculated as percentage of the mean of the respective untreated oocytes. $t$ tests between untreated and treated oocytes from all oocyte batches were then performed.

\section{Results and discussion}

To examine the effect of nitric oxide on CAT function, we expressed human CAT-1 or -2A in X. leavis oocytes where the activity of each individual transporter can be monitored against a very low background of endogenous transport. To get maximal exposure of the transporters to $\mathrm{NO}$, we followed the protocol of Zhou et al. (2010) and incubated oocytes in buffer containing $100 \mu \mathrm{M}$ of the NO donor SNAP, 10 min prior and during the transport measurement. In our initial experiments carried out at $20^{\circ} \mathrm{C}$ (the temperature routinely used for oocytes), we did not see any difference in transport activity between SNAP-exposed and control oocytes, either expressing hCAT-1 (Fig. 1a, $p=0.684, n=13-17$ ) or hCAT2A (Fig. 1b, $p=0.0827, n=12-16$ ). Sufficient NO release by SNAP was verified on norepinephrine-precontracted mouse aortic rings: as expected (Leone and Boyle 2006) 

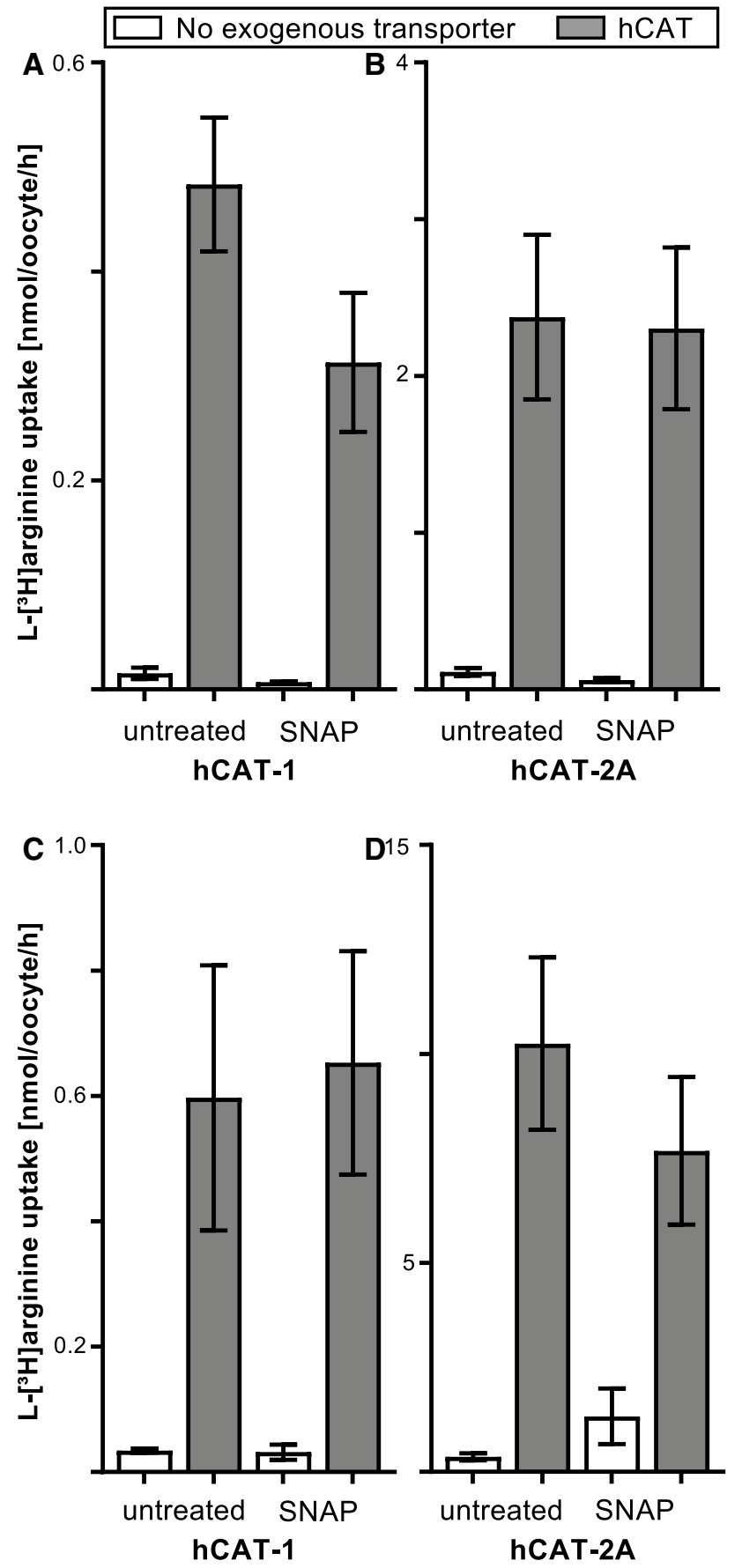

Fig. 1 hCAT-mediated transport is not altered by exposure to NO. $X$. leavis oocytes expressing hCAT-1 or hCAT-2A as indicated (dark columns) or no exogenous transporter (open columns) were exposed to $100 \mu \mathrm{M} \mathrm{S}$-Nitroso- $N$-acetylpenicillamine (SNAP) for $10 \mathrm{~min}$ in ND96 buffer or left untreated, followed by incubation in the same solution, respectively, but containing $\mathrm{L}-\left[{ }^{3} \mathrm{H}\right] \operatorname{arginine}(100 \mu \mathrm{M}$ for hCAT- 1 and $1 \mathrm{mM}$ for hCAT-2A) for $15 \mathrm{~min}$ at an incubation temperature of $20^{\circ} \mathrm{C}$ or for 1 or $3 \mathrm{~min}$, respectively, at an incubation temperature of $37^{\circ} \mathrm{C}$. Incubation temperature was $20^{\circ} \mathrm{C}(\mathbf{a}, \mathbf{b})$ and $37^{\circ} \mathrm{C}$ (c, d), respectively, for both, the $10 \mathrm{~min}$ preincubtion and the time of $\mathrm{L}-\left[{ }^{3} \mathrm{H}\right]$ arginine uptake. After intensive washing, the radioactivity per each oocyte was determined and the amount of absorbed L- $\left[{ }^{3} \mathrm{H}\right]$ arginine was calculated in nmol per hour. Columns represent means $\pm \mathrm{SD}$ ( $n=4-6$ from one representative oocyte batch) half maximal relaxation was achieved at a range of $60 \mathrm{nM}$ SNAP (data not shown).

Because CATs are mammalian proteins operating at $37^{\circ} \mathrm{C}$ under physiologic conditions, we repeated our oocyte experiments at an incubation temperature of $37^{\circ} \mathrm{C}$. However, even under this elevated temperature, we did not observe an effect of $100 \mu \mathrm{M}$ SNAP on either hCAT-1 (Fig. 1c, $p=0.853$, $n=13-16$ ) or hCAT-2A (Fig. $1 \mathrm{~d}, p=0.079, n=13-16$ ).

From these experiments, we conclude that NO has no direct effect on hCAT-mediated transport. Zhou et al. (2010) observed inhibition of L-arginine transport by $\mathrm{NO}$ generated endogenously in cardiomyocytes, indicating that NO concentrations lower than $1 \mu \mathrm{M}$ (Nakamura and Lipton 2016) are sufficient for transport inhibition. The amount of NO initially released by $100 \mu \mathrm{M}$ SNAP is about $4 \mu \mathrm{M}$ (Zhou et al. 2010). The lack of hCAT inhibition under exposure to $100 \mu \mathrm{M}$ SNAP in the $X$. leavis oocytes, thus indicates that CATs do not possess thiyl radicals that can be directly nitrosylated by NO.

Alternatively, SNO formation can occur via nitrosation, e. g. reaction of thiol with $\mathrm{NO}^{+}$or rather $\mathrm{NO}^{+}$donors (Heinrich et al. 2013) that may have been built from NO in rat cardiomyocytes, but not in $X$. leavis oocytes. To test directly if CATs are inhibited by reaction with $\mathrm{NO}^{+}$donors, we adapted the protocol developed by Daiber and co-authors (Daiber et al. 2009) who observed maximal SNO formation under a flux of $3 \mathrm{NO}$ and $1 \mathrm{O}_{2}{ }^{-}$. Such a stoichiometric release of $3 \mathrm{NO}$ and $1 \mathrm{O}_{2}^{-}$can be achieved by equimolar amounts of Sin-1 (that releases $\mathrm{NO}$ and $\mathrm{O}_{2}{ }^{-}$at equal rates) and SPENO (that generates two molecules of $\mathrm{NO}$ at the same rate) and leads to SNO formation independent of any cellular components. Exposure of $X$. leavis oocytes expressing either hCAT-1 or hCAT-2A, to $1 \mathrm{mM}$ each, Sin-1 and SPENO, did not alter their transport activity (Fig. 2, $p=0.6271$ for hCAT-1 and $\mathrm{p}=0.6951$ for hCAT-2A).

Under $1 \mathrm{mM}$ Sin-1/SPENO, about $10 \%$ of the GSH was transformed into GSNO (Supplemental Fig. 1), demonstrating that significant nitrosation had occurred. In addition, this GSNO concentration should be sufficient for transnitrosating susceptible proteins (Paige et al. 2008). These experiments demonstrate that CATs are either not directly nitrosated (or trans-nitrosated by GSNO) or SNO formation in CATs does not affect their function.

There are three alternative explanations for the discrepancy between the NO effect on rat and human CATs in cardiomyocytes and $X$. leavis oocytes, respectively: (i) Rat and human CAT-1 and CAT-2A may differ in their sensibility to $\mathrm{NO} / \mathrm{NO}^{+}$. A comparison of the amino acid sequences of rat and human CAT-1 and -2 proteins shows indeed one exclusive cysteine residue for rCAT-1 (position 202) and four exclusive cysteine residues for rCAT-2 (positions 438, 454, 620, 657). If they were responsible for the observed difference, this would imply that a 


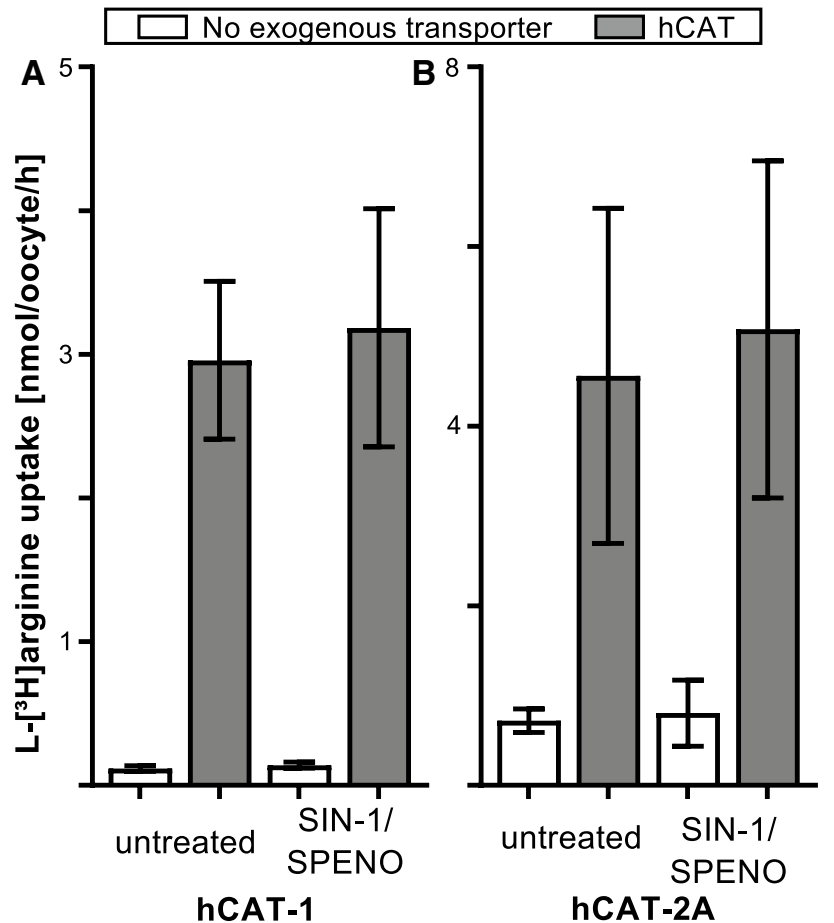

Fig. 2 hCAT-mediated transport is not altered by exposure to $\mathrm{N}_{2} \mathrm{O}_{3}$. $X$. leavis oocytes expressing hCAT-1 (A) or hCAT-2A (B) were exposed to 5-Amino-3-(4-morpholinyl)-1,2,3-oxadiazolium chloride (Sin-1) and spermine-NONOate (SPENO), $1 \mathrm{mM}$ each, for $10 \mathrm{~min}$ in ND96 buffer or left untreated, followed by incubation in the same solution, respectively, but containing $L-\left[{ }^{3} \mathrm{H}\right]$ arginine $(100 \mu \mathrm{M}$ for hCAT-1 and $1 \mathrm{mM}$ for hCAT-2A) for 1 or $3 \mathrm{~min}$, respectively. Incubation temperature was $37{ }^{\circ} \mathrm{C}$ throughout. After intensive washing, the radioactivity per each oocyte was determined and the amount of absorbed L- $\left[{ }^{3} \mathrm{H}\right]$ arginine was calculated in nmol per hour. Columns represent means $\pm \mathrm{SD}$ ( $n=6$ from one representative oocyte batch).

modulation of the transport activity would be mediated by nitros(yl)ation of completely different cysteine residues in rCAT-1 and -2. This seems rather unlikely. (ii) NO may not act directly on CATs, but rather on interacting proteins. An indirect inhibitory effect on hCAT-mediated transport has also been demonstrated for protein kinase C (PKC) (Rotmann et al. 2004). However, PKC inhibits hCATs in a variety of mammalian cells (Rotmann et al. 2007) as well as in X. leavis oocytes (Graf et al. 2001), indicating that the interacting protein responsible for PKC inhibition is rather ubiquitous. This may be different for an interacting component responsible for $\mathrm{NO} / \mathrm{NO}^{+}$-mediated CAT inhibition. (iii) Nitros(yl)ation of CATs may require a multiplex enzymatic machinery as recently reported in E. coli, where the presence of the hybrid cluster protein HCP is necessary for efficient SNO formation in a variety of proteins (Seth et al. 2018). In either case, our study implies that a membrane component (most likely an interacting protein) responsible for $\mathrm{NO} / \mathrm{NO}^{+}$-mediated CAT inhibition would be present in membrane vesicles derived from cardiomyocytes, but not in X. leavis oocytes. Further studies are required to identify such an interacting protein.

Acknowledgements Open Access funding provided by Projekt DEAL. We thank the doctoral candidate Dominik Olinger, and the group of Prof. Dr. Huige Li, for testing the NO donor SNAP on aortic mouse rings in organ baths, Alice Habermeier for quantifying GSNO concentrations in oocyte lysates by HPLC and Johanna Rupp for teaching and supervising AJH in all technical procedures. Our special thanks go to Prof. Dr. Dr. Andreas Daiber, for his professional advice concerning protein nitros(yl)ation. This work was supported by the Deutsche Forschungsgemeinschaft (Cl100/6-1 to E.I.C.).

\section{Compliance with ethical standards}

Conflict of interest The authors declare that they have no conflict of interest.

Open Access This article is licensed under a Creative Commons Attribution 4.0 International License, which permits use, sharing, adaptation, distribution and reproduction in any medium or format, as long as you give appropriate credit to the original author(s) and the source, provide a link to the Creative Commons licence, and indicate if changes were made. The images or other third party material in this article are included in the article's Creative Commons licence, unless indicated otherwise in a credit line to the material. If material is not included in the article's Creative Commons licence and your intended use is not permitted by statutory regulation or exceeds the permitted use, you will need to obtain permission directly from the copyright holder. To view a copy of this licence, visit http://creativecommons.org/licenses/by/4.0/.

\section{References}

Beyer SR, Mallmann RT, Jaenecke I, Habermeier A, Boissel JP, Closs EI (2013) Identification of cysteine residues in human cationic amino acid transporter hCAT-2A that are targets for inhibition by $N$-ethylmaleimide. J Biol Chem 288(42):30411-30419. https:// doi.org/10.1074/jbc.M113.490698

Closs EI, Boissel JP, Habermeier A, Rotmann A (2006) Structure and function of cationic amino acid transporters (CATs). J Membr Biol 213(2):67-77. https://doi.org/10.1007/s00232-006-0875-7

Daiber A, Schildknecht S, Muller J, Kamuf J, Bachschmid MM, Ullrich V (2009) Chemical model systems for cellular nitros(yl) ation reactions. Free Radic Biol Med 47(4):458-467. https://doi. org/10.1016/j.freeradbiomed.2009.05.019

Devés R, Angelo S, Chávez P (1993) N-ethylmaleimide discriminates between two lysine transport systems in human erythrocytes. J Physiol 468(5):753-766

Foster MW, McMahon TJ, Stamler JS (2003) S-nitrosylation in health and disease. Trends Mol Med 9(4):160-168

Graf P, Forstermann U, Closs EI (2001) The transport activity of the human cationic amino acid transporter hCAT-1 is downregulated by activation of protein kinase C. Br J Pharmacol 132 (6):11931200. https://doi.org/10.1038/sj.bjp.0703921

Heinrich TA, da Silva RS, Miranda KM, Switzer CH, Wink DA, Fukuto JM (2013) Biological nitric oxide signalling: chemistry and terminology. Br J Pharmacol 169(7):1417-1429. https://doi. org/10.1111/bph.12217

Leone M, Boyle WA (2006) Decreased vasopressin responsiveness in vasodilatory septic shock-like conditions. Crit Care Med 34(4):1126-1130. https://doi.org/10.1097/01.ccm.0000206466 .56669. be 
Liu X, Miller MJ, Joshi MS, Thomas DD, Lancaster JR Jr (1998) Accelerated reaction of nitric oxide with $\mathrm{O} 2$ within the hydrophobic interior of biological membranes. Proc Natl Acad Sci USA 95(5):2175-2179. https://doi.org/10.1073/pnas.95.5.2175

Lu X, Zheng R, Gonzalez J, Gaspers L, Kuzhikandathil E, Peluffo RD (2015b) Establishment of a counter-selectable markerless mutagenesis system in Veillonella atypica. Biosci Rep 29(4):271281. https://doi.org/10.1042/bsr20080159

Nakamura T, Lipton SA (2016) Nitrosative stress in the nervous system: guidelines for designing experimental strategies to study protein S-nitrosylation. Neurochem Res 41(3):510-514. https:// doi.org/10.1007/s11064-015-1640-Z

Paige JS, Xu G, Stancevic B, Jaffrey SR (2008) Nitrosothiol reactivity profiling identifies $S$-nitrosylated proteins with unexpected stability. Chem Biol 15(12):1307-1316. https://doi.org/10.1016/j. chembiol.2008.10.013

Rotmann A, Strand D, Martine U, Closs EI (2004) Protein kinase C activation promotes the internalization of the human cationic amino acid transporter hCAT-1. A new regulatory mechanism for hCAT-1 activity. J Biol Chem 279(52):54185-54192. https:// doi.org/10.1074/jbc.M409556200

Rotmann A, Simon A, Martine U, Habermeier A, Closs EI (2007) Activation of classical protein kinase $\mathrm{C}$ decreases transport via systems y+ and y+L. Am J Physiol Cell Physiol 292(6):C22592268. https://doi.org/10.1152/ajpcell.00323.2006

Seth D, Hess DT, Hausladen A, Wang L, Wang YJ, Stamler JS (2018) A multiplex enzymatic machinery for cellular protein S-nitrosylation. Mol Cell 69(3):451-464.e456. https://doi.org/10.1016/j. molcel.2017.12.025

Tsikas D, Sandmann J, Holzberg D, Pantazis P, Raida M, Frolich JC (1999) Determination of S-nitrosoglutathione in human and rat plasma by high-performance liquid chromatography with fluorescence and ultraviolet absorbance detection after precolumn derivatization with o-phthalaldehyde. Anal Biochem 273(1):32-40. https://doi.org/10.1006/abio.1999.4209

Zhou J, Kim DD, Peluffo RD (2010) Nitric oxide can acutely modulate its biosynthesis through a negative feedback mechanism on L-arginine transport in cardiac myocytes. Am J Physiol Cell Physiol 299(2):C230-239. https://doi.org/10.1152/ajpcell.00077.2010

Publisher's Note Springer Nature remains neutral with regard to jurisdictional claims in published maps and institutional affiliations. 